\title{
Immobility in Rio de Janeiro, beyond poverty
}

\author{
Benjamin Motte-Baumvol ${ }^{1}$ \\ benjamin.motte@u-bourgogne.fr \\ UMR 6049 THEMA \\ CNRS, Université Bourgogne Franche-Comté \\ 4, boulevard Gabriel \\ 21000 Dijon, France \\ and \\ Carlos D. Nassi \\ nassi@pet.coppe.ufri.br \\ Transportation Engineering Program \\ Federal University of Rio de Janeiro \\ Bloco H-106, P.O.Box 68512 \\ 21941-972, Rio de Janeiro, RJ, Brazil
}

${ }^{1}$ Corresponding author 
We examine immobility in Rio de Janeiro using the 2002/2003 Household Travel Survey

$>$ Almost half of inhabitants made no trips at all during the day

$>$ Income has only a slight effect on the probability of being immobile

$>$ Unemployed workers and homemakers have the greatest number of immobile

$>$ Strong geographic dimension of immobility is due to demographic structure effects 


\section{Immobility in Rio de Janeiro, beyond poverty}

\section{Introduction}

Average levels of individual mobility in Brazilian cities are low, in terms of both kilometers traveled and number of trips made. An initial review of the 2002/2003 Rio de Janeiro Metropolitan Area (RJMA) Household Travel Survey (HTS) (CENTRAL 2005) suggests very high levels of immobility. While immobility is sometimes mentioned in studies on Latin American cities (Vasconcellos 2005; Ureta 2008), immobility has never been studied as a subject in itself, despite the fact that it is a major characteristic of these cities. We have undertaken such a study, and results are presented in this article.

According to the $2002 / 2003$ HTS $^{1}$ nearly half of RJMA residents (46\%) did not travel at all during the day. This degree of immobility is much higher than that observed in European countries, where it is between 10 and 26 percent, depending on the country, sources, and population studied (Hubert et al. 2008). The figure for another major Brazilian metropolitan area, São Paulo, is similar: Vasconcellos (2005) observes that the level of immobility there varies from 24 to 55 percent depending on individuals' income level.

Poverty is often cited as an explanation for these high levels of immobility in Brazilian cities (CENTRAL 2005; Vasconcellos 2005), without specifying exactly which characteristics of poverty or impoverished populations ${ }^{2}$ lead to immobility. There are very few examples of research on the subject of immobility, and those that do exist concentrate on measuring degrees of immobility rather than studying its characteristics and causes (Madre et al. 2007; Hubert et al. 2008).

Examining the literature on the connections between poverty and mobility, one notable review of which is given by Fol (2009), we can identify several potential explanations for immobility. First, low incomes lead people to limit or avoid certain trips that are too costly. Next, income tends to affect the number of trips for certain purposes, notably those for purchases and health services, which are less numerous in poorer populations. Finally, impoverished populations are less mobile overall. They are affected by spatial mismatch (Kain 1968) which limits their access to employment, as well as their social capital (Putnam 1995; Putnam 2000), and by diminished motility (Kaufmann et al. 2004) in the neighborhoods where they live.

In the city of Rio de Janeiro, which is strongly segregated, the poorer part of the population is concentrated in the North and the richer part in the South. This segregation could potentially

\footnotetext{
$1 \quad$ The Rio de Janeiro HTS does take into account all trips, associated with a purpose, unless walking trips of less than 300 meters.

2 The category "poor" is questionable, and subject to criticism. Not only does this category say nothing about the processes that lead to social inequality and poverty, but it is also very vague and depends on geographic and historical context (Paugam and Duvoux, 2008). Impoverished individuals experience a partial lack of social representation or are denigrated as dependent on social programs (Farge et al., 2002). Nonetheless, we use the term "poor" (and its variants) in this article, both for simplicity and because it can today be connected with a statistical definition of poverty that allows comparative analysis.
} 
manifest itself as a strong geographic dimension to immobility, which would be very present in the North while the South would be situated at the level of large European cities.

Our results partially contradict this hypothesis, as we find that, all other things equal, individuals in the northern zone of Rio de Janeiro are not more immobile than those in the South. For example, an unemployed man around thirty years of age with a high school level of education has the same probability of being immobile no matter where he lives. Nevertheless, immobility remains much higher in the North, because of the socio-demographic and activity structure of the populations who live there. Indeed, an analysis of the Rio de Janeiro HTS shows that more so than income, employment status is the principal factor behind immobility. The northern zone is home to more homemakers and unemployed workers, and almost 80 percent of people in these two categories are immobile.

\section{Less mobility among the poor}

\subsection{Mobility is unequally distributed}

Over the course of recent decades, mobility has experienced rapid growth, particularly in North America and Europe, driven by growing vehicle ownership (Orfeuil 2000). The United States is much more mobile than other countries, because motorization took place earlier and was more intense (Fol 2009). The distances traveled per capita there are almost twice those observed in France (Orfeuil 2000). In Brazil, a low level of car ownership (almost eight times lower than in the US, with 110 versus 830 cars per 1000 inhabitants) (Lopes 2005) leads to lower overall mobility. The number of trips per person per day is 1.77 in Rio de Janeiro in 2002/2003 (CENTRAL 2005), as compared to an average of 4 in the United States (Pucher and Renne 2003) and 3.5 in the Paris region (called lle-deFrance) (DREIF 2004). This corresponds to an average travel distance of 14.8 kilometers per day per inhabitant in São Paulo, as opposed to 17.5 kilometers for an inhabitant of Ile-de-France. The number of trips by car is particularly low in Brazilian cities: 0.3 trips per day per person in Rio de Janeiro and 0.6 in São Paulo, compared to 1.5 in Paris.

The different forms of mobility and in particular automobile mobility (Urry 2007) require economic resources, and this is a source of inequality between individuals. Indeed, many studies show that access to mobility varies from one social group to another, particularly because access to an automobile is dependent upon income (Hivert 1999; Pucher and Renne 2003; Vasconcellos 2005). The poorest households (with incomes below 250 reals $^{3}$ per month) have low levels of automobile ownership, with less than one in ten owning a car, as opposed to one in two for the richest households. They use the car for only $12.1 \%$ of trips as opposed to $66.1 \%$ for the richest group (with incomes above 3600 reals per month) (Vasconcellos 2005). This also leads to strong differences in travel distance. Among the poorest individuals in Rio de Janeiro, even public transit use is limited, and almost 60 percent of trips are made on foot (CENTRAL 2005).

Such clear income-based differences in mobility are not found in French cities (Olvera et al. 2004; Paulo 2006). While trip distance is lower for poorer populations, in general they still have access to

$3 \quad$ The minimum wage was 240 reals per month in April 2003. It increased to 545 reals in March 2011. The value of the Brazilian real has fluctuated greatly since 2003 . The exchange rate was $\$ 1=3,53$ reals on January 1, 2003, and \$1=1,7 reals in March 2011. 
automobiles. The average number of trips for poor and rich households is comparable, with the exception of work-related trips. In large Brazilian cities like São Paulo and Rio de Janeiro, the poorest populations have an average number of trips almost half that of the rich (CENTRAL 2005; Vasconcellos 2005). These strong differences can be explained by the greater income differences between the rich and the poor, but also by their higher levels of unemployment and differences in employment status that lead to a lower number of work-related trips.

One of the most extreme expressions of income-related mobility disparity is the very high proportion of immobile individuals, i.e. those that make no trips at all: $46.6 \%$ of the inhabitants of Rio de Janeiro according to 2004/2005 HTS data. The level of immobility in Brazilian cities is particularly high in comparison with those observed in European countries, which are generally situated between the values of $17.4 \%$ in France and 22\% in the United Kingdom (Madre et al. 2007, Hubert et al. 2008). For Vasconcellos (2005), the reason that values are so high in Brazilian cities is probably to be found in the very low income of a large part of the population, as well as unemployment and underemployment. In Rio de Janeiro, the percentage of immobile individuals reaches $54.3 \%$ among the poor, as compared to $32.9 \%$ among households earning more than 20 times the minimum wage (CENTRAL 2005). In the São Paulo HTS, we observe the same kind of differences between the richest and poorest households. Among the poorest individuals, immobility reaches $55 \%$ while it is only $24 \%$ in the richest category of individuals (Vasconcellos 2005).

\subsection{Spatial mismatch, neighborhood effects, and social capital}

Besides the income and underemployment of poorer populations, very high levels of immobility could be explained by the spatial mismatch hypothesis and the intense concentration of poverty in certain neighborhoods and areas. The spatial mismatch hypothesis (Kain 1968) has long been used in North American research to address the absence or low level of mobility among poor households, as well as the living conditions and social trajectory of these households. These households' weak or nonexistent mobility is considered particularly problematic there (Bacqué, Fol 2007, Fol 2009). It is considered to be a consequence of segregation processes combined with the decentralization of employment, which together increase the distance between poorer populations and employment opportunities, reducing both their chances of finding a job (Holzer et al. 1994) and their ability to travel.

In the municipality of Rio de Janeiro, the principal employment centers are in the south area and downtown (figure 2), whereas the poor population is concentrated in the northern neighborhoods (Marques et al. 2008) where unemployment is particularly high. We would thus expect to observe high levels of immobility there. However, the spatial mismatch theories are controversial. In the end, spatial mismatch is only a secondary factor in the higher risk of unemployment for individuals who are members of ethnic minorities, for whom the principal barriers to employment are education, qualifications, and child care (Blumenberg and Manville, 2004). Thus, spatial mismatch might have but a very limited impact on general mobility, and particularly on immobility (Fol et al. 2007).

Looking beyond spatial mismatch, the concentration of poor populations in certain neighborhoods tends to create a "social isolation" similar to that observed in inner cities in the United States, as well as certain neighborhoods of French cities (Wilson 1987, Le Breton 2005). Within the Rio de Janeiro municipality, the hilly landscape contributes to the separation of the northern neighborhoods (that are home to a large number of people living in extreme poverty) from the richer southern 
neighborhoods (Marques et al. 2008). According to Putnam (2000), the poor neighborhoods and the people who live there possess little social capital ${ }^{4}$ because spatial and social isolation deprive them of contact with people from other social groups. Openness to other social groups allows access to employment and social success. Thus, the concentration of impoverished households in the northern zone of Rio de Janeiro could make an even greater number of them immobile, perhaps through a "contagion" as postulated by Crane (1991) or low social capital (Putnam 1995, Coleman 2007). However, these ideas are contested (Bordreuil 1998, Imbroscio 2008) and analyses give mitigated and sometimes contradictory results (Marpsat, Laurent, 1997). In the end, existing work does not conclusively link lower mobility levels with neighborhood effects, beyond a simple income-related lack of access to automobiles. Here again we might discover that belonging to a certain neighborhood has a limited effect on the number of trips made by the populations who live there, and on their immobility levels.

The explanation for these uncertain results is probably to be found in the fact that the spatial mismatch hypothesis and Putnam's social capital approach (Putnam 2000) ignore or underestimate the degree of local solidarity and the strength of social networks in impoverished neighborhoods. Many studies show that these networks and other forms of solidarity play an essential role in the daily life of inhabitants (Barnes 2003), notably in issues concerning mobility (Coutard et al. 2002, Fol et al. 2007), including the search for employment (Chapple 2001). Additionally, distance to the workplace is not necessarily a barrier to employment in poor neighborhoods, considering that job markets for the least qualified people are primarily local (Shen 2001).

Mobility has grown in our societies not only because it has become technically easier but also because it has social value (Rémy 1996). But the "injunction to be mobile conflicts partially with the experience of poor households and the concrete strategies they apply to confront poverty" (Bacqué and Fol, 2007). These strategies do not necessarily require the transformation of potential mobility into actual mobility, as shown by studies on the subject (Kaufmann et al. 2004), and this leads to a reduced number of trips among certain categories of the population, specifically poor households.

For certain authors defending a new paradigm of mobility (Hannan et al., 2006; Urry, 2007; Adey, 2010; Cresswell, 2010), mobility and immobility are "neither a dualism nor an opposition rather a relational continuum" (Pellegrino 2011). Mobility has a respiration-like rhythm (Creswell 2010) that manifests through periods of relative immobility during which the individual remains active. For Urry (2007), mobility requires these "mooring" phases to remain fluid over time and space. Depending on the scale of analysis, locality or proximity can be mistaken for immobility.

Individuals belonging to poor households tend to connect mobility and proximity in a particular way, relying more heavily on proximity (Bacqué, Fol 2007, Fol 2009). This necessarily leads to reductions in travel distance, which are clearly observed among the poorer population of several countries, including Brazil. But it may also result in a lower observed number of trips and even apparent immobility when the means for measuring mobility (the Household Travel Surveys) are not designed to record short-range travel on foot. We shall examine this problem more closely and describe the data used in this study below.

$4 \quad$ Social capital is defined as a set of ties and norms facilitating coordination and cooperation within a group or a society (Putnam 2000, after Bacqué and Fol 2007). 


\section{Studying immobility using 2002/2003 Household Travel Survey (HTS) data}

\subsection{The RJMA, a territory with 11 million inhabitants}

The Rio de Janeiro household travel survey took place between October 2002 and December 2003, with a sample of 34,000 households participating in face-to-face interviews. These households are distributed throughout the entire RJMA, which had an estimated population of 11.3 million in 2003. The RJMA includes 20 municipalities, and stretches over 120 kilometers from east to west, and $50 \mathrm{~km}$ in the north-south direction. The municipality of Rio de Janeiro is the largest and most populous one in the metropolitan area, with around 53.8 percent of the population and roughly the same proportion of jobs.

The geography of human settlement in the RJMA is characterized first and foremost by its coastal location facing the Atlantic Ocean, surrounding the Guanabara Bay. Next, population distribution can be understood in connection with the very hilly terrain throughout the RJMA. The steepest hills have quite low population or none at all, creating very low-density areas in the heart of the city, only a few hundred meters from the center.

Figure 1: Population density of municipalities in the Rio de Janeiro Metropolitan Area

Source: Cartography by the authors from the Rio de Janeiro HTS 2002-2003

\subsection{Almost 100,000 people interviewed}

Out of the 99,300 individuals interviewed for the Rio de Janeiro HTS we analyzed 97,536, excluding records with incomplete information and those where incoherency was found in the household characteristics. Women make up 52.9\% of the sample. There are more women in higher age groups, which can be explained by shorter life expectancy for men and a sharp peak in their mortality between 15 and 25 years of age, due largely to violence.

The RJMA population has several notable characteristics. First, employment is low $(52,3 \%)$ among individuals between 18 and 60 years of age. In Ile-de-France this figure is $73.4 \%$. Low employment is explained by the number of unemployed people and homemakers among the 18-60 year old population in the RJMA. These two categories make up 15.2 and 16.6 percent of this age class, as compared to 9.1 and 4.1 percent in Ile-de-France. Next, the population of the RJMA is younger overall than that of Ile-de-France, but the difference is rather small. Thus, we find a somewhat smaller percentage of the population is aged 60 or over ( $14 \%$ of the total RJMA population as opposed to $16.2 \%$ in IDF) and the proportion of children under 15 years old is $20.5 \%$ as opposed to the $19.8 \%$ observed in lle-de-France.

\subsection{Low levels of mobility revealed by the Rio de Janeiro Household Travel Survey}

The HTS reveals that the inhabitants of the RJMA have a low level of mobility: only 19 million trips are carried out daily, or 1.77 per capita, and for more than $46 \%$ of survey participants no trips were reported at all. For the sake of comparison, a mobile employed person in RJMA carries out on average 2.4 trips per day, while this figure is over 3.7 for an inhabitant of the Paris region. The least mobile inhabitants of the RJMA are those over 60 years of age and the lowest-income category, with averages of 1.2 and 1.5 trips per day, respectively. 
Another striking characteristic of the cariocas' ${ }^{5}$ mobility is the modal split. Only 15 percent of trips are carried out by car, as compared to $44 \%$ in Ile-de-France. The automobile's small mode share stands in contrast with that of public transport, which carries $46.4 \%$ of trips as compared to $19.4 \%$ in Ile-de-France. Finally, we note that the share of walking trips is practically equal in the two cities, at around $34 \%$ of trips.

\subsection{High levels of immobility: a result of survey methods?}

The immobility figures for Rio de Janeiro and São Paulo are both over 45\%, considering the whole of the population, and are much higher than those observed in European cities, which vary from 16.9 to 22.6 percent of individuals (Hubert et al. 2008). The extreme poverty which affects a large part of the Brazilian population would seem to be a major explanation for these differences. However, two principal differences in survey methods also exist between European travel surveys and those in Rio de Janeiro.

The first difference is in the interview samples. The Rio de Janeiro HTS concerns the entire population, including the youngest children, whereas European surveys do not take everyone into account and use different age cutoffs. Hubert et al. (2008) take into account all individuals over 15 years of age in their comparison of three European countries. Applying this threshold to the RJMA, the percentage of immobile individuals remains the same, at $47 \%$ of the population. Thus, the inclusion of very young individuals in the survey does not contribute at all to the high level of immobility observed in the RJMA.

The second difference in methods is less obvious, and while its effects are not directly measurable they certainly exist. The Rio de Janeiro HTS does not count walking trips of less than 300 meters. The Paris HTS reveals that $5.3 \%$ of the population there did not make any trip of over 300 meters. However, the absence of complementary quantitative or qualitative surveys specifically dealing with the RJMA prevents us from evaluating the effect of this methodological choice on the measurement of immobility. We will see below that the categories of people most likely to be considered immobile are homemakers and the elderly, two categories for whom we also observe many short-range trips on foot near the home.

Despite these methodological differences, the magnitude of the difference in immobility between Brazilian and European cities is still surprising. We recall that the HTS is but a snapshot of individual mobility on a particular day, and does not take into account life rhythms and forms of organization that occur over periods of several days (Axhausen et al. 2002; Axhausen et al. 2007) which can vary greatly from one place or country to another. For example, an individual who is immobile on one day might be mobile every other day of the week. HTS that observe individual mobility over several days find levels of mobility of only $5 \%$ to $8 \%$ of the population (Chlond et al. 1999; Axhausen et al. 2002; Axhausen et al. 2007) and very similar values in the various places studied (Madre et al. 2007).

\subsection{Two contrasting territories in Rio de Janeiro}

To study the connection between poverty and immobility in more detail, we have compared two areas of the Rio de Janeiro municipality. These two zones are on one hand a vast area containing

5 Cariocas are inhabitants of the municipality of Rio de Janeiro. 
$1,288,000$ inhabitants in the northern, poorer part of the city, and on the other hand an area containing 872,000 inhabitants in the south, the richest part of the city. As the individual income variable in the Rio de Janeiro HTS is of insufficient quality, this comparison is a means to evaluate the effects of poverty on immobility.

The outlines of the two zones were defined based on the "traffic zone" divisions (CENTRAL 2005) specific to the Rio de Janeiro HTS, which are larger than census tracts. This is why the outlines we have chosen seem to deviate slightly from the geography of income in the Rio de Janeiro municipality. We also note that the outlines we use are chosen to assure that the two study zones include a sufficient number of HTS data points to allow a detailed comparison.

Table 1: Distribution of "Traffic Zones" in the municipality of Rio de Janeiro by average household income level

Figure 2: Average household income in the municipality of Rio de Janeiro

Source: Cartography by the authors from the Rio de Janeiro HTS 2002-2003

The "northern zone" includes some of the poorest neighborhoods in the city, where average incomes are below 700 reals per month, but also areas with intermediate incomes, between 700 and 1600 reals. The "southern zone" includes a few areas with intermediate average incomes, but is essentially composed of zones whose average revenue is high ( $>1600$ reals). The principal favelas present in the south of the city are not included in the "southern zone" as we have drawn it.

\section{Structural immobility}

Immobility in Rio de Janeiro is strongly correlated with the poverty that affects a large part of the population. In households with a minimum wage income, $54.3 \%$ of individuals are immobile. As opposed to only $32.9 \%$ for those individuals in households earning twenty times the minimum wage. But the income levels themselves do not seem to be a major explicative factor of the probability of being immobile in our analysis. Immobility depends more on employment status and the demographic structure of impoverished populations.

\subsection{Employment status highly correlated with immobility level}

Immobility takes on very different values depending on individuals' employment status. It varies from $80 \%$ for the least mobile individuals - homemakers and unemployed workers - to a little over $20 \%$ for the most mobile people, employed workers and students. This is fairly intuitive: we note a strong opposition between the individuals who are most likely to have an activity outside the home (students and employed workers) and those who are least likely to have obligatory trips away from the home (homemakers, unemployed workers, the retired, and young children).

Figure 3: percentage of immobile individuals by employment status and location of residence

A clear contrast can be observed between the northern and southern zones of the Rio de Janeiro municipality, with the level of immobility reaching $50 \%$ in the North as opposed to $32 \%$ in the South. This distinction between the richer and poorer parts of Rio de Janeiro can be observed for every individual employment status. It is only among employed workers that the difference is very small. 


\subsection{The principal factors behind individual immobility are individual characteristics}

The variables that contribute the most to the probability that an individual is immobile are all individual characteristics, rather than ones related to a household or a place of residence.

Among individual characteristics, employment status plays a major role in determining immobility. On one hand, we find students and employed workers whose level of immobility is low, and on the other hand unemployed or inactive workers, homemakers, and retirees or pensioners who have very high levels of immobility. We note that unemployment has a very strong effect on immobility among workers. Among those who do have a job, being employed in the formal economy greatly minimizes the probability of being immobile relative to employment in the informal sector or non-contractual work.

The probability of being immobile varies with age and education level. The more education a person has, the lower the probability of being immobile, while inversely mobility decreases as age increases.

The position within the family has a very strong effect on the probability of being immobile. Spouses (other than the "reference person" or "head of household") and children have a much higher probability of being immobile. This probability is even higher in the case of family members (other than parents and children) living with the household.

Table 2: Logistic model: immobile individuals in the Rio de Janeiro HTS

\subsubsection{Household characteristics have only a limited effect on the probability of being immobile}

Among the many variables that characterize households, few of them have significant connections with the dependent variable (immobility). For example, household automobile ownership is not significant, though for those individuals who did make at least one trip in the day, the distance and number of trips depends on the number of cars in the household. The only household variable having a strong, significant link with the probability of immobility is the number of children (or the total number of individuals in the household), which is positively correlated with the probability of immobility.

Another household characteristic that appears to explain the level of immobility is income. However, interviewees often declined to answer this question, and there seems to be a tendency to underdeclare among the richest households. Because of this fact, this variable was not retained for our model.

\subsubsection{Connections between territories and immobility are limited}

Living in a low-density area, in a single-family house, and particularly in the peripheral areas of the RJMA tends to increase the probability of being immobile. These effects are slight but an overall trend does emerge: immobility is more frequent where density is lower.

Finally, since the household income data are of questionable quality, we have employed another variable that provides information on the average income in the household's place of residence, derived from the census. It indicates that individuals residing in areas with upper-middle incomes have a lesser tendency to be immobile. Nonetheless, this variable has low explicative power. 


\subsection{A comparison of the northern and southern zones: structural effects of population on the level of immobility}

The influence of income on mobility is central to our initial question, but this variable appears only very marginally in the results obtained above. It seems that poverty, when expressed in terms of household income level, is only weakly connected to individual immobility. However, our comparison of the northern and southern parts of the city leaves no doubt that immobility is much more common in the northern, poorer area. Applying the model for the entire RJMA to a sample including only the population of these two areas reveals that, all other things being equal, living in one or the other of these areas has no significant connection with individual immobility (appendix 1).

Thus, we hypothesize that the differences in immobility observed between these two territories can be explained by differences in socio-demographic composition. The connection between poverty and immobility would be only indirectly connected to differences in income, and more directly connected to the very different characteristics of poorer and richer populations. The demographics of the "northern zone" are notable for a greater number of individuals from categories with high levels of immobility, such as homemakers and unemployed workers. The "northern zone" is also characterized by a lower level of education, a higher number of children per household, and the predominance of single-family homes. All of these factors are linked with high levels of immobility. On the other hand, the socio-demographic composition of the "southern zone" tends toward lower levels of immobility.

Table 3: Distribution of individuals by employment status (columns are in percent)

The employment status of individuals, which is a particularly important variable affecting immobility, reveals differences between the northern and southern zones. On one hand, in the north of the city there is a greater number of homemakers and inactive workers (table 3 ). These are the two categories of people who have the highest levels of immobility. On the other hand, in the south it is employed workers and students who are more numerous, and these are the two groups with the lowest percentage of immobility.

Table 4: Distribution of individuals according to number of children in the household (columns are percent)

Table 5: Distribution of individuals by education level (columns are percent)

Employment status is not the only characteristic unequally distributed between the north and the south that contributes to a higher level of immobility in the northern, poorer part of the city. The "northern zone" also has a greater number of large families having two or more children (table 4), and its population generally has a low level of education. Almost 90 percent of the population has only primary or secondary education (table 5). Inversely, in the "southern zone" people are generally more educated, and $50.3 \%$ of people have finished secondary or at least some postsecondary education. Level of education is thus a major difference between the poorer northern neighborhoods and the richer south.

Table 6: Distribution of employed workers by employment type (columns are percent)

Table 7: Distribution of individuals by age (columns are percent)

Some other individual characteristics that are unequally distributed between the north and the south tend on the other hand to moderate the immobility differences between the two study zones. First 
and foremost for employed workers, this is the employment type (table 6). Though workers employed in the informal sector have high levels of immobility and are more present in the "northern zone", the category "other" which includes heads of businesses and independent professionals has even higher levels of immobility and is found predominantly in the southern zone. Finally, the population of the northern zone is younger than that of the southern zone (table 7), and immobility increases with age.

\section{Discussion, Conclusion}

In Rio de Janeiro, nearly half of inhabitants interviewed were found to carry out no travel during the day. This value is much higher than those observed in major European cities, where it does not exceed one in five inhabitants. We were curious about the causes of this very high level of immobility, as well as its individual and social consequences.

\subsection{The principal factors explaining high levels of immobility in Rio de Janeiro}

Immobility is explained primarily by characteristics of individuals and their households (rather than those of their place of residence). Employment status is the strongest determining factor. The greatest difference is observed between employed workers and students, only 20 percent of whom were immobile, and homemakers and inactive workers, 80 percent of whom were immobile. The figure is around 70 percent for retirees and pensioners. A low level of education, advanced age, and large families are also factors that substantially increase the probability that an individual is immobile. On the other hand, all other things being equal, household income has only a very weak effect on the probability of being immobile. Poverty as expressed by income is not a factor capable of directly explaining high levels of immobility. Nonetheless, we find employment type and level of education to be among the principal determinants of immobility. These are also factors behind poverty.

For this reason, there is a clear difference between the northern zone of Rio de Janeiro, where lowincome populations are located, and the southern zone, where the richest inhabitants live. The former is characterized by a high level of immobility (nearly $50 \%$ of the population made no trips) while this figure is a little over $32 \%$ in the latter. This geographic dimension to immobility is connected to a particular population structure. The northern zone has a large number of homemakers and unemployed workers, and an overall low level of education. But the high levels of immobility in the northern zone are not at all a consequence of neighborhood effects. These effects, which are contested by numerous authors (Bordreuil 1998, Imbroscio 2008) are not found to influence the probability of being immobile, once the effects of individual and household characteristics have been accounted for.

The southern zone still shows levels of immobility above those observed in major European cities. Here again, immobility is explained by the presence of homemakers and unemployed or inactive workers, who are less numerous than in the northern zone. This zone also has a large proportion of retirees and pensioners. We also observe that the employment structure of the southern zone of Rio de Janeiro is different from that in lle-de-France in that the percentage of employed workers is 10 points lower (48.1\% as opposed to $57.5 \%$ among the population over 14 years old). This could also be one of the factors explaining the higher degree of immobility in Rio de Janeiro. Several authors have 
pointed out the percentage of active workers and professional trips as factors capable of explaining differences in mobility level, especially when they vary with income (Olvera et al. 2004, Paulo 2006).

Questions surrounding measurement techniques and travel characteristics may also help explain high levels of reported immobility. The Rio de Janeiro HTS does not count trips of less than $\mathbf{3 0 0}$ meters made on foot. This restrictive definition of a "trip" is characteristic of an HTS intended to measure phenomena relevant to transport engineering, rather than social phenomena. A certain number of trips are thus excluded from observation, and it is impossible to quantify them as there is no point of comparison: urban travel is measured in the same way throughout Brazil. In Paris, where the HTS records all trips over one minute long, we find that $5.3 \%$ of people made only walking trips of less than $\mathbf{3 0 0}$ meters during the day. In Rio de Janeiro, this percentage could be even greater because overall travel distances are lower than those in Paris, and more trips should therefore be less than 300 meters. In addition, the proportion of active workers is lower in Rio de Janeiro, and home-work commuting trips are among the longest ones, so the number of individuals who may have made only trips less than $\mathbf{3 0 0}$ meters in length should be higher. Finally, the hilliness and narrow streets of certain neighborhoods, such as the hillside favelas, probably result in a large number of short-range trips on foot, as the use of motorized travel modes is difficult there. However, the northern neighborhoods that we concentrated on do not contain such steep slopes. Measurement methods must also play a role in the level of immobility observed in Rio de Janeiro, but this effect is difficult to quantify.

\subsection{The individual and social consequences of immobility}

In a society that values mobility (Rémy 1996), being immobile means finding oneself excluded, on the fringes of society. Additionally, a large percentage of immobile people could be a sign that a society is functioning poorly, with fewer connections existing between individuals. From this perspective, the levels of immobility seen in Rio de Janeiro seem particularly troubling. However, the literature tends to question these kinds of conclusions, countering them with examples of the concrete strategies used by impoverished households. These strategies do not necessarily include the transformation of potential mobility into actual mobility (Kaufmann et al. 2004), but tend to combine mobility and locality in a particular fashion, taking advantage of resources in close proximity to the home (Bacqué and Fol 2007, Fol 2009). Thus, the Rio de Janeiro HTS, which does not count walking trips of less than 300 meters, does not allow us to truly measure the individual and social consequences of immobility, which could only be evaluated with the help of a complementary survey.

Nonetheless, it is possible based on our results to envisage political responses to what might be considered excessive levels of immobility. Some reactions might concern the transport and urban planning sectors, though it is probable that they would have little effect. These measures could include better public transport service for the neighborhoods where immobile populations are concentrated, the construction of streets that better connect certain neighbourhoods to employment centres, or the creation of over- or underpasses across the major infrastructures that can truly function as barriers for the local population (Turner 2007). Finally, income-based subsidies for transport passes and system-wide integrated ticketing are possible responses to low levels of mobility. But responses targeting the transportation sector would likely have little effect. The low level of access to automobiles does not appear to be a major factor behind immobility, and neither do financial or temporal difficulties in accessing public transport. Much immobility is observed in 
dense areas that are well-served by public transport, and income levels have only a limited effect on the probability of being immobile.

Appropriate political responses to excessive immobility would instead aim for changes in the labor market and the level of education. A drop in unemployment, an increase in economic activity, and an increase in employment among women would all doubtlessly have a considerable effect on immobility. Since 2003, decreases in unemployment, an increase in employment in the formal sector have most likely led to a significant decrease in immobility, and an increase in education level, particularly in poorer neighborhoods, would allow additional change in this direction.

\section{$\underline{\text { References }}$}

Axhausen, K., Löchl, M., Schlich, R., Buhl, T., Widmer, P., 2007. Fatigue in long-duration travel diaries. Transportation 34(2), 143-160.

Axhausen, K.W., Zimmermann, A., Schonfelder, S., Rindsfuser, G., Haupt, T., 2002. Observing the rhythms of daily life: A six-week travel diary. Transportation 29(2), 95-124.

Bacqué, M., Fol, S., 2007. Inequality Regarding Mobility: Observations and Policies. Swiss Journal of Sociology 33(1), 89-104.

Barnes, S., 2003. Determinants of individual neighborhood ties and social resources in poor urban neighborhoods. Sociological spectrum 23(4), 463-497.

Blumenberg, E., Manville, M., 2004. Beyond the spatial mismatch: welfare recipients and transportation policy. Journal of Planning Literature 19(2), 182-205.

Bordreuil, J., 1997. Les gens des cités n'ont rien d'exceptionnel, In: Collectif (Ed.), En marge de la ville: ces quartiers dont on parle. La Tour d'Aigues: Éditions de l'aube, pp. 231-251.

CENTRAL, 2005. Plano Diretor de Transporte Urbano da Região Metropolitana do Rio de Janeiro. Resultado da pesquisa origem/destino. Rio de Janeiro: Companhia Estadual de Engenharia de Transportes e Logística (Governo do Estado do Rio de Janeiro).

Chapple, K., 2001. Time to work: Job search strategies and commute time for women on welfare in San Francisco. Journal of Urban Affairs 23(2), 155-173.

Chlond, B., Lipps, O., Manz, W., Zumkeller, D., 1999. Auswertung zum Deutschen Mobilitäts-Panel 1998/1999: Haushaltsbefragung zur Alltagsmobilität in verschiedenen Raumtypen, Final report FEProjekt 70569/98 to the Bundesminister für Verkehr. Karlsruhe: Universität Karlsruhe.

Coleman, J., 1988. Social capital in the creation of human capital. American Journal of Sociology 94(Supplement), 95-120.

Coutard, O., Dupuy, G., Fol, S., 2002. Suburban poverty: local dependance or automobile dependance?: Spaces, directions for use. Espaces et sociétés 2002(108-109), 155-175.

Crane, J., 1991. The epidemic theory of ghettos and neighborhood effects on dropping out and teenage pregnancy. American Journal of Sociology 96, 1226-1259. 
DREIF, 2004. Les déplacements des franciliens en 2001-2002. Enquête Globale de Transport. Paris: Direction Régionale de l'Equipement d'lle-de-France.

Farge, A., Laé, J., Cingolani, P., Magloire, F., 2004. Sans visages. L'impossible regard sur le pauvre. Paris: Bayard.

Fol, S., 2009. La mobilité des pauvres. Paris: Belin.

Fol, S., Dupuy, G., Coutard, O., 2007. Transport policy and the car divide in the UK, the US and France: Beyond the environmental debate. International Journal of Urban and Regional Research 31(4), 802818.

Hivert, L., 1999. Le parc automobile des ménages, étude en fin d'année 1999 à partir de la source" Parc Auto" SOFRES, Rapport de convention INRETS-ADEME. Arcueil: INRETS.

Holzer, H.J., Ihlanfeldt, K., Sjoquist, D.L., 1994. Work, search, and travel among white and black youth. Journal of Urban Economics 35(3), 320-345.

Hubert, J., Armoogum, J., Axhausen, K., Madre, J., 2008. Immobility and Mobility Seen Through TripBased Versus Time-Use Surveys. Transport Reviews 28(5), 641-658.

Imbroscio, D., 2008. United and actuated by some common impulse of passion: challenging the dispersal consensus in american housing policy research. Journal of Urban Affairs 30(2), 111-130.

Kain, J.F., 1968. Housing segregation, negro employment, and metropolitan decentralization. The Quarterly Journal of Economics 82(2), 175-197.

Kaufmann, V., Bergman, M., Joye, D., 2004. Motility: mobility as capital. International Journal of Urban and Regional Research 28(4), 745-756.

Le Breton, E., 2005. Bouger pour s'en sortir. Mobilité quotidienne et intégration sociale. Paris: Armand Colin.

Lopes S., 2005, Elaboração de Modelos Matemáticos para Análise, Avaliação e Previsão do Comportamento da Motorização no Brasil, Thesis (PhD), Department of Transportation Engineering, Rio de Janeiro: Federal University of Rio de Janeiro.

Madre, J.L., Axhausen, K.W., Brög, W., 2007. Immobility in travel diary surveys. Transportation 34(1), 107-128.

Marpsat, M., Laurent, R., 1997. Le chômage des jeunes est-il aggravé par l'appartenance à un quartier en difficulté ?, In: Collectif (Ed.), En Marge de la ville : ces quartiers dont on parle. La Tour d'Aigues: Éditions de l'aube, pp. 321-348.

Marques, E., Scalon, C., Oliveira, M.A., 2008. A comparison of social structures in Rio de Janeiro and Sao Paulo. Dados Revista de Ciencias Sociais 51(1), 215-238.

Olvera, L.D., Mignot, D., Paulo, C., 2004. Daily mobility and inequality: the situation of the poor. Built Environment 30(2), 153-160. 
Orfeuil, J., 2000. L'évolution de la mobilité quotidienne:(comprendre les dynamiques, éclairer les controverses). Arcueil: Institut national de recherche sur les transports et leur sécurité.

Paugam S., Duvoux N., 2008, La régulation des pauvres, Paris: Presses universitaires de France.

Paulo C., 2006, Inégalités de mobilités: disparité des revenus, hétérogénéité des effets, Thesis (PhD), Department of Economics, Lyon: Université Lumière - Lyon II.

Pucher, J., Renne, J.L., 2003. Socioeconomics of urban travel: evidence from the 2001 NHTS. Transportation Quarterly 57(3), 49-77.

Putnam, R., 1995. Bowling alone: America's declining social capital. Journal of democracy 6, 65-65.

Putnam, R.D., 2000. Bowling alone: The collapse and revival of American community. New York: Simon and Schuster.

Rémy, J., 1996. Mobilités et ancrages: vers une autre définition de la ville, In: Hirschorn, M., Berthelot, J.M. (Eds.), Mobilités et ancrages. Vers un nouveau mode de spatialisation ? Paris: L'Harmattan, pp. 135-153.

Shen, Q., 2001. A spatial analysis of job openings and access in a US metropolitan area. J. Am. Plan. Assoc. 67(1), 53-68.

Turner, B.S., 2007. The enclave society: towards a sociology of immobility. European journal of social theory 10(2), 287-303.

Ureta, S., 2008. To Move or Not to Move? Social Exclusion, Accessibility and Daily Mobility among the Low-income Population in Santiago, Chile. Mobilities 3(2), 269-289.

Urry, J., 2007. Social Inequalities in Network Capital. Swiss Journal of Sociology 33(1), 9-26.

Vasconcellos, E.A., 2005. Transport metabolism, social diversity and equity: The case of São Paulo, Brazil. Journal of Transport Geography 13(4), 329-339.

Wilson, W.J., 1987. The truly disadvantaged: The inner city, the underclass, and public policy. Chicago: Chicago University Press. 
Table 1: Distribution of "Traffic Zones" in the municipality of Rio de Janeiro by average household income level

\begin{tabular}{|l|c|c|c|}
\hline Income per household & North & South & All RJMA \\
\hline Low (<700 reals) & 56,7 & 0,0 & 55,2 \\
\hline Medium & 43,3 & 13,1 & 29,8 \\
\hline High (>1 600 reals) & 0,0 & 86,9 & 15,0 \\
\hline All & 100,0 & 100,0 & 100,0 \\
\hline
\end{tabular}

Source: Calculated by the authors from the National Population Census 2000 and the Rio de Janeiro HTS 20022003

Table 2: Logistic model: immobile individuals in the Rio de Janeiro HTS

\begin{tabular}{|c|c|c|c|c|c|}
\hline & & & Standard & Wald & \\
\hline & & Estimate & Error & Chi2 & Pr>Chi2 \\
\hline \multicolumn{2}{|l|}{ Intercept } & $-0,83$ & 0,14 & 34,58 & $* * *$ \\
\hline \multirow[t]{5}{*}{ Employment status } & Employed & 0,65 & 0,08 & 71,62 & $* * *$ \\
\hline & Unemployed & 2,70 & 0,05 & 2787,57 & $* * *$ \\
\hline & Homemaker & 2,42 & 0,06 & 1852,54 & $* * *$ \\
\hline & Retiree or pensioner & 2,15 & 0,06 & 1369,79 & $* * *$ \\
\hline & Other & 2,41 & 0,09 & 692,09 & $* * *$ \\
\hline \multirow[t]{3}{*}{ Employment type } & Formal employment & $-1,12$ & 0,06 & 297,98 & $* * *$ \\
\hline & Informal employment & $-0,41$ & 0,07 & 32,10 & $* * *$ \\
\hline & Other & 0,18 & 0,07 & 6,85 & $* *$ \\
\hline \multirow[t]{4}{*}{ Position in the family } & Spouse (i.e. not reference & & & & \\
\hline & person) & 0,41 & 0,03 & 183,95 & $* * *$ \\
\hline & Child & 0,46 & 0,04 & 163,00 & $* * *$ \\
\hline & Other relative & 0,99 & 0,04 & 551,93 & $* * *$ \\
\hline \multirow[t]{4}{*}{ Education level } & Primary & $-0,43$ & 0,06 & 47,65 & $* * *$ \\
\hline & High school & $-0,63$ & 0,06 & 97,14 & $* * *$ \\
\hline & Some university + & $-0,86$ & 0,07 & 155,56 & $* * *$ \\
\hline & Other & $-0,45$ & 0,21 & 4,47 & $*$ \\
\hline \multirow[t]{5}{*}{ Age } & $20-29$ years & 0,18 & 0,05 & 14,82 & $* * *$ \\
\hline & $30-39$ years & 0,20 & 0,05 & 13,53 & $* * *$ \\
\hline & 40-49 years & 0,34 & 0,06 & 38,45 & $* * *$ \\
\hline & $50-59$ years & 0,53 & 0,06 & 82,64 & $* * *$ \\
\hline & 60 years and over & 0,59 & 0,06 & 91,66 & $* * *$ \\
\hline \multicolumn{2}{|l|}{ Physical disability } & 0,44 & 0,07 & 43,63 & $* * *$ \\
\hline \multirow[t]{2}{*}{ Children } & 1 child & 0,15 & 0,03 & 29,71 & $* * *$ \\
\hline & 2 children & 0,32 & 0,03 & 126,38 & $* * *$ \\
\hline \multicolumn{2}{|l|}{ Car ownership } & 0,04 & 0,02 & 2,64 & \\
\hline \multirow{2}{*}{$\begin{array}{l}\text { Income level of the } \\
\text { place of residence }\end{array}$} & Low & $-0,01$ & 0,02 & 0,08 & \\
\hline & High & $-0,28$ & 0,03 & 71,26 & $* * *$ \\
\hline \multicolumn{2}{|c|}{ Population density in place of residence } & $-0,01$ & 0,00 & 90,86 & $* * *$ \\
\hline \multirow[t]{2}{*}{ Building type } & Apartment & $-0,71$ & 0,12 & 37,79 & $* * *$ \\
\hline & House & $-0,61$ & 0,11 & 28,84 & $* * *$ \\
\hline
\end{tabular}

Signif. codes: 0 “*** $0.001^{(* * \prime} 0.01^{\prime * \prime} 0.05$ '? $0.1^{\prime \prime \prime} 1$

Source: Calculated by the authors from the Rio de Janeiro HTS 2002-2003 
Table 3: Distribution of individuals by employment status (columns are in percent)

\begin{tabular}{|l|c|c|c|}
\hline \multirow{2}{*}{ Employment status } & \multicolumn{2}{c|}{$\begin{array}{c}\text { North - } \\
\text { Poor }\end{array}$} & \multicolumn{2}{c|}{ South - Rich } & \multicolumn{1}{c|}{ All RJMA } \\
\hline Student & 9,8 & 12,2 & 10,8 \\
\hline Employed & 38,5 & 48,1 & 42,2 \\
\hline Unemployed & 14,4 & 5,8 & 12,5 \\
\hline Homemaker & 16,2 & 9,2 & 15,0 \\
\hline $\begin{array}{l}\text { Retiree or } \\
\text { pensioner }\end{array}$ & 19,3 & 23,6 & 17,9 \\
\hline Other & 1,8 & 1,2 & 1,5 \\
\hline All & 100,0 & 100,0 & 100,0 \\
\hline
\end{tabular}

Source: Calculated by the authors from the Rio de Janeiro HTS 2002-2003

Table 4: Distribution of individuals according to number of children in the household (columns are percent)

\begin{tabular}{|c|c|c|c|}
\hline Children & $\begin{array}{l}\text { North - } \\
\text { Poor }\end{array}$ & South - Rich & All RJMA \\
\hline None & 25,6 & 38,7 & 26,1 \\
\hline 1 child & 29,8 & 28,5 & 28,8 \\
\hline $\begin{array}{l}\mathbf{2} \text { children and } \\
\text { more }\end{array}$ & 44,6 & 32,7 & 45,1 \\
\hline All & 100,0 & 100,0 & 100,0 \\
\hline
\end{tabular}

Source: Calculated by the authors from the Rio de Janeiro HTS 2002-2003

Table 5: Distribution of individuals by education level (columns are percent)

\begin{tabular}{|l|c|c|c|}
\hline \multicolumn{1}{|c|}{ Education level } & $\begin{array}{c}\text { North - } \\
\text { Poor }\end{array}$ & $\begin{array}{c}\text { South - } \\
\text { Rich }\end{array}$ & All RJMA \\
\hline Illiterate & 3,1 & 1,2 & 3,3 \\
\hline Primary & 47,7 & 19,8 & 46,7 \\
\hline High school & 38,2 & 28,4 & 33,9 \\
\hline Some university + & 10,9 & 50,3 & 15,8 \\
\hline Other & 0,2 & 0,3 & 0,3 \\
\hline All & 100,0 & 100,0 & 100,0 \\
\hline
\end{tabular}

Source: Calculated by the authors from the Rio de Janeiro HTS 2002-2003

Table 6: Distribution of employed workers by employment type (columns are percent)

\begin{tabular}{|l|c|c|c|}
\hline \multicolumn{1}{|c|}{ Employment type } & \multicolumn{1}{c|}{$\begin{array}{c}\text { North - } \\
\text { Poor }\end{array}$} & Rich & All RJMA \\
\hline Formal Employment & 61,8 & 58,1 & 57,7 \\
\hline $\begin{array}{l}\text { Informal } \\
\text { employment }\end{array}$ & 14,1 & 8,6 & 17,0 \\
\hline Other & 24,1 & 33,3 & 25,3 \\
\hline All & 100,0 & 100,0 & 100,0 \\
\hline
\end{tabular}

Source: Calculated by the authors from the Rio de Janeiro HTS 2002-2003

Table 7: Distribution of individuals by age (columns are percent)

\begin{tabular}{|c|cc|}
\hline & $\begin{array}{c}\text { North - } \\
\text { Poor } \quad \text { South - Rich All RJMA }\end{array}$ \\
\hline
\end{tabular}




\begin{tabular}{|l|c|c|c|} 
Less than $\mathbf{2 0}$ years & 10,6 & 7,1 & 10,6 \\
\hline $\mathbf{2 0 - 2 9}$ years & 19,9 & 18,1 & 20,8 \\
\hline $\mathbf{3 0 - 3 9}$ years & 18,6 & 15,9 & 18,7 \\
\hline $\mathbf{4 0 - 4 9}$ years & 17,6 & 18,5 & 18,3 \\
\hline $\mathbf{5 0 - 5 9}$ years & 14,6 & 16,4 & 13,9 \\
\hline $\mathbf{6 0}$ years and over & 18,8 & 23,9 & 17,6 \\
\hline All & 100,0 & 100,0 & 100,0 \\
\hline
\end{tabular}

Source: Calculated by the authors from the Rio de Janeiro HTS 2002-2003

Appendix 1: Logistic model: immobile individuals in Rio de Janeiro north and south areas

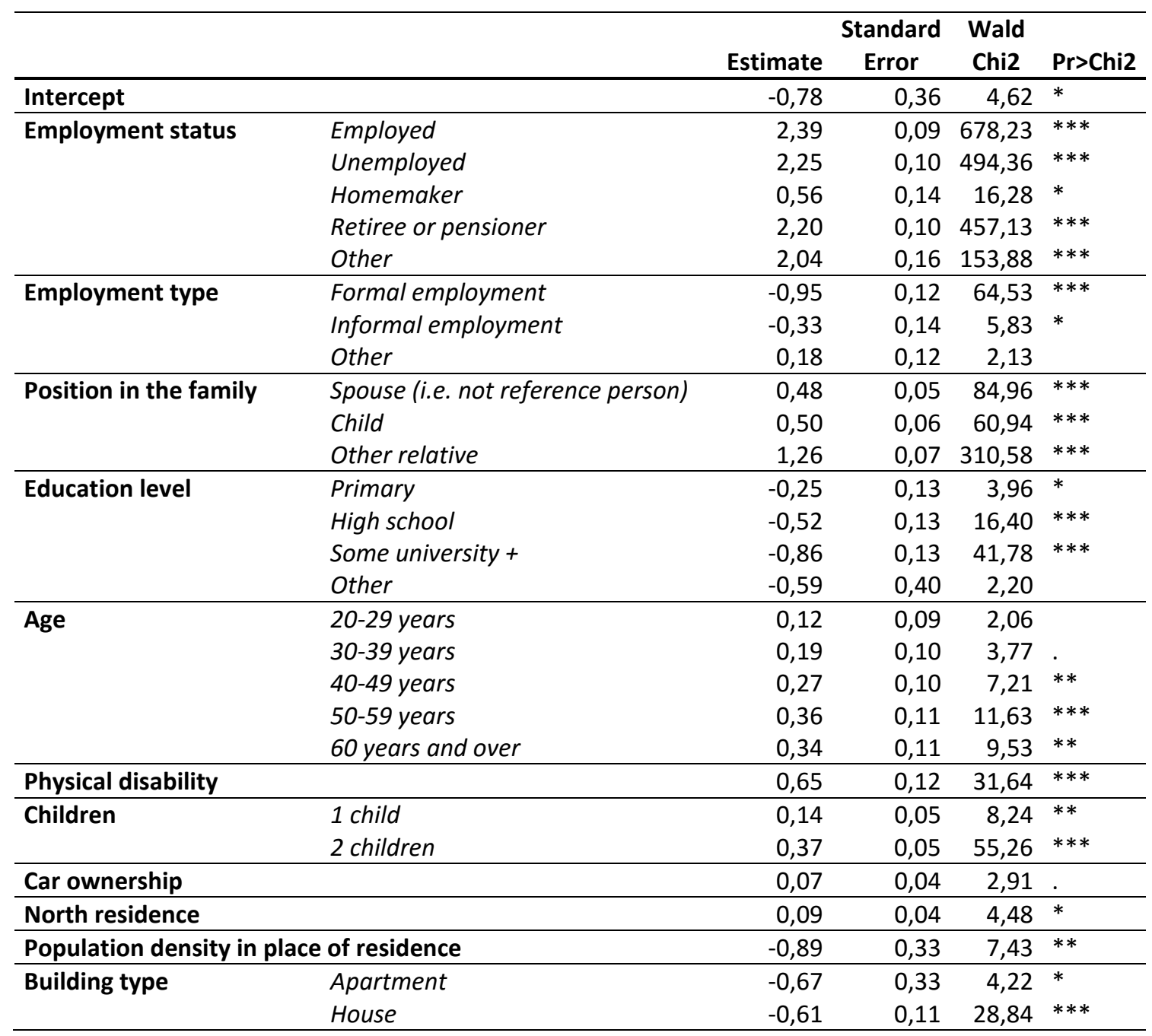

Signif. codes: 0 “*** $0.001^{\prime * * \prime} 0.01^{\prime * \prime} 0.05$ '. $0.1^{\prime \prime} 1$

Source: Calculated by the authors from the Rio de Janeiro HTS 2002-2003 